\title{
I. Facts and observations relating to the connexion between vascular and extra-vascular substances in living organized bodies
}

\section{Anthony Carlisle F.R.S. F.A.S. F.L.S.}

To cite this article: Anthony Carlisle F.R.S. F.A.S. F.L.S. (1815) I. Facts and observations relating to the connexion between vascular and extra-vascular substances in living organized bodies, Philosophical Magazine Series 1, 46:207, 3-7, DOI: 10.1080/14786441508638480

To link to this article: http://dx.doi.org/10.1080/14786441508638480

曲 Published online: 27 Jul 2009.

Submit your article to this journal $\pi$

Џll Article views: 2

Q View related articles $₫$ 


\section{PHILOSOPHICAL MAGAZINF}

\section{AND JOURNAL.}

1. Facts and Observations relating to the Commexion letueen vascular and extra-vascular Substances in living organizen Bodies. By Antrony Caklisla, Surgeon Exiraordinary to His Royal Highness the Prince Regent, and His Royal Highness the Duke of Glouccsler, F.R.S. F.A.S. F.L.S. हैं $\varepsilon^{\circ} \mathrm{C}$.

To Mr. Tilloch.

SrR, - T He following memoir having been partially made known to the public, 1 beg yon to lay it before your scientific readers, as a means of preventing misrepresentation or piracy. I am, sir, Your most obedient servant,

Swho Square, July 4, 1815 .

Anthony Carlisle.

General or comparative anatomy, the great branch of natural knowledge on which the rationale of medical art is founded, has lately risen in estcem, and is every day more accurately and more extensively cultivated. Considering how intinately the discoveries of new facts, their relation to each other, and the physiological inferences to be drawn from them, are connected with the previous establishment of definite views, of clear intelligible terms, and of strict physical methods; and feeling the importance of the present subject, I hasten to submit this memoir to competent judges. I am aware that premature generalization of facts as well as premature inductions from them, are seldom useful; and 1 should not have troubled the scientific inquirer with this communication had I not felt assured that the present state both of anatomy and physiology would authorise it. In my statements I shall purposely avoid all metaphysical Vol. 46. No. 207. July 1815. A2

prctension 
pretension to dive into the hidden mystery of vitality, confessing myself wholly incompetent to reduce that power within the rules of physical science: a power which appears to my judgement as allied to the nature of an inscrutable First Cause or an emanation from it.

The vast variety in substances, textures, bulk, and combinations, which the living animal and vegetable kingdoms exhibit, render it difficult to define the essential residence of life as connected with any of the modes of organic structure. Some of the compounds and textures of animals are known to be more important for the maintenance of life than others ; as the cerebral substance and the muscular textures: but there is a numerous tribe of living bodies that appear to be wholly destitute of those peculiar parts; of which the entire vegetable kingdom may be adduced as an instance. Habits of meditation and research have led me to conclude, that some benefit may arise to physiology from more accurate discriminations between the several substances of living bodies, especially as to the relative dominion of vitality or physical causes on those substances respectively.

The active phanomena of life appear to be generally distinct from those of physical catisation, but the passive condition of living substances is not so obvious. The suspended action of torpid animals and vegetables, and the latent vitality of many of the more simply constructed animals and vegetables during the clssence of heat and moisture, show the intimate connexions wilich subsist between vitality and physical causes. Difficult and intricate as these investigations may seem when extended to all thite cases of vital phrnomena, they are not so in the grosser exaniples to be now adduced; and if it should be found that many sulbstances uistinctly continuous with vital organic bodies are wholly sulijccted to physical dominion, and that several other substances are in part influenced by the one cause and by the ovher, it may perhaps open new and more precise views in the medical art. Those parts of organic bodies which have no power of seli-repair, which hold no continuity with the circulating fluid material dastined to replenish the waste, to augment the bulk, or repair the accidents of the living fabric, may be jus!ly deemed extra-vital. The exuvial defences or coverings of animals are of this kind; namely, hairs, naiis, feathers, and all cuticular structures, as well as the epidermoid coverings and liusks of the vegetable kingdom : some of those substances which are destined to be worn away, retain a partial continuity with the organic system of circulating fluids, as the growing bulbs of hairs, the roots and laminæ of nails and hoofs; whilst other parts which are destined to be shed, as feathers and cuticular scales, are wholly detached from the vascular communion after their complete 
complete formation, and only shere mechanically to the hiving parts for a time.

The most ayjosite illutrations and the most positive instanes; of union between vital and extra-vitsl parts are to be found in the trataceous tirio of animals. Atter a long contimed and carefu! investipetion, $1 \mathrm{am}$ fully convinced that the shells of at the Vermes on Linneus are extra-vaseular from their commencement, and remain so during the whole of their connexion with the living creature. The first production and the growth of those shells always depend upon a deposit of material thrown out from the surface of the body of the living animal. The figure and colonr of the several pats of those shells in evary species depend upon the shape and the colouring glands of the modelling organs. Fractures are rcpaired by spreading a cretaceous fluid over the inner edges, and never by any exudation from the fractured parts, since they retain always the squared broken surfaces after such repairs. Extraneous bodies are equally covered with shell, whether they are in contact with the parent shell or not. T'he first may be seen in the frequent envelopment of Nere'des in the common oyster; the latter has becn often ascertained by experiments made for the purpose of creating artificial pearls, and which might, if skilfully practised, yet prove very successful. The borings of parasitical vernes into shells are never filled up, or the bored surfaces altered, unless such borings penetrate into the cavity where the living animal dwells, and then the apertures are universally plugged up or smeared over with pearly matter. The water-worn external surfaces of old shells and other external abrasions are never repaired, which is to be seen in old living oysters exposed to the moving friction of currents or strong tides, in the worn-off spines of the Pholas Dactylus and in the convex puints of the two valves of old Mytili; especially the Mytilus anatimus. I have sought in the most extensive collections of the metropolis for examples of fractures, and other injuries which hare occurred to the shells of living vermes, and I have coflected many remarkable specimens: they all demonstrate the same results withont any exception. I have made nuntrous experiments upon the garden snail Helix nemoralis, by fracturing and breaking away the shell in various parts, and have always found the repairs to be effected from within and by smearing orer an epidermoid varnish, and then by plastering the inner surface of that film with successive calcareous laminæ. I have in vain attempted to inject the shells of recent vermes from the vascular parts of their bodies, and am fully satisfied that none of their albuminous or gelatinous testaceous membranes were ever at any time traversed by vessels: indeed they do not possess any of the reticular texture or arA 8 borescent: 
borescent pores which are common to all vascular parts, but microscopically examined they resemble the exuvial or epidermoid meinbranes. 'To these may be added, the notorious circumstance of tire unchangeableness of the outer surfaces of testaceous shelis during their growth, and the continued renewal of their other surfaces which admit of contact with the living inhabitant; next, the stains and coloured transudations which they often derive from metallic salts, and other colouring materials placed in their vicinity; and lastly, that such occurrences do not affect the living animal. The mechanical connexion or contact that subsists between the living animals which occupy the testaceous shells and their extraneous dwellings is in many instances very slender. The common oyster possesses its first pair of valves, consisting of single lamina, before it quits the parental organs; a muscle passes between the centres of the concavity of each shell adhering to each, and it acts upon the valves nearly at right angles. The animal has no other continuity with the shell: at the hinge an elastic substance is wedged in, the spring of which is excited by compression; but it does not possess the property of extension beyond the passive state: when dried this substance cracks into cubes. As the animal grows it.augments the margin of its shells, and thickens them by adding new lamine on their insides; the muscular adhesion glides forward, still keeping the centre of the valves. The elastic substance at the hinge is augmented along the inner surfaces only, and must have been always deposited during the expanded state of the valves, since the limits of its elastic condition is exactly adapted to that state. As the lamine of the shells increase, there is a gap at the outsile of the hinge, filled with soft crumbling and decomposing worn-out elastic ligament. This gap presents two inclined planes which meet in an acute angle; and that space is kept free from pebbles and hard extraneous bodies by the presence of the decomposing ligament, as such an accident would prove fatal, by preventing the opening of the valves. The growth of all testaceons shells aftords remarkable proofs of their extravascular formation. The muscular adhesions are generally the only points of continuity between the animal and its shell, and these are constantly changing with the augmentations of bulk. In all the conoid univalves which revolve upon spiral axes, the successive parts of the shell are merely spread upon the older parts without any intermixture of their substances, and the epidermoid or extraneous bodies are alike involved in the successive folds. In the other classes of animals similar phænomena occur. The calcareous shells of birds' eggs are merely deposited upon the membrana putamenis, and the inner portionts are regularly crystallized prisms, the long diameters of which point to 
the centre of the egg. These shells are wholly extra-vascular. and their albuminous membranes are alike cuticular, whilst the inner true membrana putaminis is made reticular and capable of vascular organization. The order of deposit in these examples is like that of enamel in teeth, which appears to be precipitated upon the bone of the touth under the guidance of a membranous case or mould. From a disordered fowl, I have seen eggs produced the calcareous crusts of which were inflated with bubbles, so as to form a cancellated shell in texture like pumicestone. The most durable substances of aninal bodies, such as the bones and teeth, are only partly vascular, since their calcareous materials are fixed by chemical precipitants, and remain under chemical laws. Injuries done to the horns of cattle, to the hoofs of animals, and to human nails, are never restored; those parts do not possess the power of self-repair, and it is only by mechanical wearing away that such injuries are obliterated. Indeed, the beneficent construction of animal nature is sufficiently manifested in the insensibility of all the exuvial coverings, and in the inorganic composition of many parts which are exposed to mechanical attrition ; as the enamel of teeth, the horny beaks of birds, and the cuticular or horny coverings of feet. The same beneficence appears to be extended to many parts of the external organic substances by which painful sensations are obviated; while the substances themselves, being left directly under the dominion of the vital superintendancy, become more permanent:- such parts are the tendous ligaments, cartilages, cellular tissue, the gelatine and lime of bones. Even water is an essential constituent of the animal fluids, and affords the necessary softness and flexibility to the solids.-But this subject and its comnexion with the vegetable composition and texture extends far beyond the limits of a memoir, and I must therefore suspend my observations.

[To be continued.]

II. Description of a new Reflecting Compass. By $\mathrm{Mr}$. T. Jones, 62, Charing Cross, London.

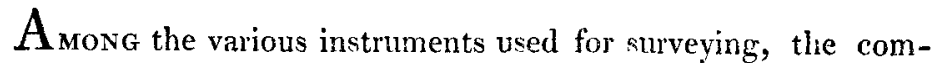
pass appears to have beenl least considered; and this has probably arisen from its want of portability when furnished with a stand, and the conviction that under the most favouralle circumstances it is far inferior to the theodolite; and yet requires equal care in its adjustment and use.

But in military sketching, in the delineation of roads, rivers, $\& \mathrm{c}$. and in all surveys where rapidity is more an object than $\epsilon x$ treme accuracy, the compass will be found a most valuable aux- 